\title{
DESEMPENHO DE SEMEADORA-ADUBADORA EM FUNÇÃO DO PREPARO DE SOLO E ESPAÇAMENTO DA CULTURA DO MILHO ${ }^{1}$
}

\author{
Carlos Alessandro Chioderoli ${ }^{2}$, Carlos Eduardo Angeli Furlani² ${ }^{2}$, Rouverson Pereira da Silva ${ }^{2}$, \\ Douglas de Castilho Gitti ${ }^{3}$, Flávio Hiroshi Kaneko³ ${ }^{3}$ Rodrigo Alberto Alândia Roman ${ }^{4}$
}

\begin{abstract}
PERFORMANCE OF A GRAIN DRILL IN FUNCTION

OF SOIL TILLAGE AND MAIZE CROP SPACING

The performance of machines and agricultural implements are of fundamental importance, especially when subjected to different types of soil tillage, and have to adapt to these conditions, in order to promote good operational performance. The objective of this study was to analyze the operational performance of a Marchesan Supreme Cop grain drill, equipped with four rows, spaced $0.90 \mathrm{~m}$, according to three types of tillage: conventional tillage (plowing and two harrowing series), reduced tillage (scarification with a roller), and no-tillage, in areas previously seeded with maize (Zea mays L.), at two spacing measures $(0.90 \mathrm{~m}$ and $0.45 \mathrm{~m})$. The results indicate that the demand for power, tensile stress, and motor rotation, in the sowing operation, were not influenced by tillage and maize crop. The tractor wheel slip showed different results, being lower in no-tillage and higher in conventional and reduced tillage.
\end{abstract}

KEY-WORS: Zea mays L.; sowing; operational capacity; wheel slip; agricultural machinery.

\section{INTRODUÇÃO}

O preparo convencional do solo vem sendo substituído pelo preparo conservacionista e pelo sistema semeadura direta, visando à maior conservação dos solos, maior capacidade operacional e diminuição de custos. Os sistemas de manejo do solo podem ser classificados como intensivo (convencional com uso de arados e grades), conservacionista (escarificador) e semeadura direta. Furlani (2000) encontrou mais de $75 \%$ de cobertura do solo, no preparo com escarificador, demonstrando ser este um sistema conservacionista, pois, conforme ASAE (1982), sistemas com

\section{RESUMO}

O desempenho de máquinas e implementos agrícolas é de fundamental importância, principalmente quando estão sujeitos a diferentes tipos de preparo de solo, tendo que se adaptar a estas condições para promover uma boa capacidade operacional. Objetivou-se, com este trabalho, analisar o desempenho operacional de semeadora-adubadora Marchesan Cop Suprema, equipada com quatro fileiras, com espaçamento 0,90 m, em função de três tipos de preparo do solo: convencional (aração e duas gradagens), reduzido (escarificação com rolo destorroador) e semeadura direta, em área anteriormente semeada com milho (Zea mays L.), em dois espaçamentos $(0,90 \mathrm{~m} \mathrm{e}$ $0,45 \mathrm{~m}$ ). Os resultados indicam que a exigência de potência, força de tração e rotação do motor, na operação de semeadura, não foram influenciadas pelo preparo do solo e cultivo do milho. A patinagem dos rodados do trator apresentou diferenças, sendo menor na semeadura direta e maior no preparo convencional e reduzido.

PALAVRAS-CHAVE: Zea mays L.; semeadura; capacidade operacional; patinagem; máquinas agrícolas.

mais de $30 \%$ de cobertura podem ser denominados conservacionistas.

As técnicas do sistema de semeadura direta são complementos das atuais técnicas de conservação do solo, que envolvem menor mobilização e remoção do solo e maior quantidade de restos vegetais na superfície, apresentando, como vantagem, a redução dos custos operacionais de mecanização, além dos aspectos conservacionistas de redução das características físicas, químicas e biológicas do solo (Nagaoka \& Nomura 2003).

Segundo Garcia et al. (2006), é importante conhecer a capacidade da máquina, a fim de selecionar

1. Trabalho recebido em out./2009 e aceito para publicação em nov./2010 (n registro: PAT 7647/ DOI: 10.5216/pat.v40i4.7647).

2. Universidade Estadual Paulista "Júlio de Mesquita Filho", Faculdade de Ciências Agrárias e Veterinária, Departamento de

Engenharia Rural, Jaboticabal, SP, Brasil.E-mails: ca.chioderoli@uol.com.br, furlani@fcav.unesp.br, rouverson@fcav.unesp.br.

3. Universidade Estadual Paulista "Júlio de Mesquita Filho", Faculdade de Engenharia, Departamento de Fitotecnia,

Socioeconomia e Tecnologia de Alimentos, Ilha Solteira, SP, Brasil.E-mails: gittidouglas@hotmail.com, fhkaneko@hotmail.com.

4. Universidade Estadual Paulista "Júlio Mesquita Filho", Faculdade de Ciências Agrárias e Veterinária, Departamento de Fitossanidade, Jaboticabal, SP, Brasil. E-mail: alandiaroman@gmail.com. 
a potência e os equipamentos que desempenharão as operações agrícolas em tempo hábil, evitando-se, desta forma, custos adicionais com máquinas superdimensionadas, que são comuns em propriedades agrícolas. O desempenho de máquinas agrícolas é importante para a correta execução das operações, dentre elas, a semeadura direta (Cortez et al. 2005). Os mesmos autores afirmam que o uso de culturas de cobertura (milheto e sorgo) não afeta o desempenho do conjunto trator-semeadora-adubadora.

Portanto, no sistema semeadura direta, no qual não ocorre o preparo convencional do solo, acentua-se a importância de uma semeadora que atenda aos preceitos básicos de cortar a massa vegetal e depositar corretamente a semente e o fertilizante, para se obter melhores produtividades. Com relação à velocidade de semeadura, Cepik et al. (2005) observaram que ocorre variação da força de tração, com o aumento da velocidade, em Argissolo Vermelho distrófico, na condição de umidade friável, observando-se a menor força de tração $(1,3 \mathrm{kN})$ na menor velocidade $\left(4,5 \mathrm{~km} \mathrm{~h}^{-1}\right)$, à profundidade de $12 \mathrm{~cm}$. Os autores verificaram aumento de patinagem $(15 \%)$, com a maior velocidade de semeadura $\left(6,5 \mathrm{~km} \mathrm{~h}^{-1}\right)$.

Da Rosa et al. (2008) encontraram maior esforço de tração em hastes sulcadoras de semeadoras que atuaram em áreas com maior grau de compactação, caracterizadas por tempo maior após a realização de uma escarificação. Ao avaliar o desempenho de uma semeadora-adubadora de fluxo contínuo, Furlani et al. (2002) concluíram que a potência exigida na barra foi maior no preparo do solo escarificado do que no preparo convencional e plantio direto.

Assim, o objetivo do presente trabalho foi avaliar o desempenho operacional de uma semeadora-adubadora, na semeadura do milho, equipada com quatro fileiras, em função de três tipos de preparo do solo (convencional, conservacionista e semeadura direta), em área anteriormente cultivada com milho, em dois espaçamentos $(0,90 \mathrm{~m}$ e $0,45 \mathrm{~m})$.

\section{MATERIAL E MÉTODOS}

O experimento foi conduzido na área experimental do Laboratório de Máquinas e Mecanização Agrícola da Universidade Estadual Paulista (Unesp), Campus de Jaboticabal, no Estado de São Paulo, localizada nas coordenadas $21^{\circ} 14^{\prime}$ 'S e $48^{\circ} 16^{\prime} \mathrm{W}$, com altitude média de 560 metros, declividade média de $4 \%$ e clima Aw (subtropical), de acordo com a classificação de Köppen. O solo da área experimental foi classificado como Latossolo Vermelho eutroférrico típico (Embrapa 2006).

Para a coleta dos dados, foi utilizado um trator Valtra, modelo BM 100, 4x2 TDA, com potência de 73,6 kW (100 cv). Para a semeadura, foi utilizada semeadora-adubadora de precisão, da marca Marchesan, modelo COP Suprema, com quatro fileiras de semeadura, dotada de disco de corte para palhada de $18 "(45,7 \mathrm{~cm})$ e haste sulcadora de adubo com as seguintes características: $2,7 \mathrm{~cm}$ de espessura da ponteira; $1,0 \mathrm{~cm}$ de espessura da haste; e ângulo de ataque de $20^{\circ}$. As características dos equipamentos utilizados são apresentadas na Tabela 1 .

O delineamento experimental utilizado foi em blocos casualizados, em esquema fatorial $3 \times 2$, com 6 tratamentos e 4 repetições, totalizando 24 parcelas, e três sistemas de preparo do solo (convencional, conservacionista e semeadura direta), combinados com dois espaçamentos da cultura do milho $(0,45 \mathrm{~m}$ e $0,90 \mathrm{~m}$ ).

A determinação da força na barra de tração foi obtida por meio de uma célula de carga M. SHIMIZU, modelo TF400. A potência média na barra de tração foi determinada de forma indireta, utilizando-se a equação

$$
P B=\frac{F_{m} \cdot v}{1000}
$$

em que $P B=$ potência na barra de tração $(\mathrm{kW}) ; F_{m}=$ força de tração na barra $(\mathrm{kN}) ; v=$ velocidade real de deslocamento $\left(\mathrm{m} \mathrm{s}^{-1}\right)$; e $1000=$ fator de adequação.

Tabela 1. Características dos equipamentos utilizados.

\begin{tabular}{ccccc}
\hline Equipamento & Arado & Grade niveladora & Escarificador & Semeadora-adubadora \\
\hline \multirow{2}{*}{ Marca/Modelo } & Marchesan-Tatu & Piccin & Jumbo Mati & Marchesan/Cop \\
& JMHD-7 & Suprema \\
\hline \multirow{2}{*}{ Órgãos ativos } & 3 discos & 32 discos de & 7 hastes, rolo & 4 fileiras com haste \\
& (reversíveis) de 26” & $18 ”$ & destorroador & escarificadora \\
\hline
\end{tabular}


A potência de pico $(\mathrm{kW})$ correspondeu aos maiores valores obtidos pela combinação da força de tração e sua correspondente velocidade de deslocamento, registradas e armazenadas pelo sistema de aquisição de dados, durante o deslocamento do conjunto trator-semeadora-adubadora, dentro de cada parcela experimental. A potência por linha de semeadura foi calculada tomando-se como base a potência média na barra, dividida pelo número de fileiras da semeadora-adubadora.

Para a determinação da rotação da TDP (tomada de potência), foi utilizado um conjunto formado por roda denteada, por onde passa feixe de luz, produzindo 60 pulsos por volta, e sensor ótico instalado na própria TDP. O equipamento foi colocado no eixo da TDP do trator e os dados obtidos foram armazenados pelo sistema de aquisição. Para medição da velocidade real, utilizou-se uma unidade de radar, localizada na lateral direita do trator, tipo RVS II, com inclinação de $45^{\circ}$ em relação ao solo. Para determinar a rotação dos rodados, cada roda do trator foi munida de um sensor, sendo o pulso de cada roda apresentado individualmente. Assim, a patinagem foi obtida pelos sensores geradores de pulsos, os quais permitiram o cálculo, por meio da equação apresentada por Silva (2000).

A massa seca da palhada do milho presente no solo, resultante da semeadura anterior, realizada no espaçamento de $0,45 \mathrm{~m}$, com semeadora contendo 7 fileiras, e no espaçamento de $0,90 \mathrm{~m}$, com 4 fileiras, foi obtida coletando-se a palha em área de $0,25 \mathrm{~m}^{2}$, sendo este material, posteriormente, colocado em estufa elétrica com circulação forçada, a $105^{\circ} \mathrm{C}$, por 48 horas, e os valores extrapolados para $\mathrm{kg} \mathrm{ha}^{-1}$.

Os dados foram submetidos a análise de variância (teste F) e as médias comparadas pelo teste Tukey, a 5\% de significância.

\section{RESULTADOS E DISCUSSÃO}

A potência na barra de tração não apresentou diferença estatística $(p>0,05)$ entre os tipos de preparo do solo (convencional, escarificação e semeadura direta) e nos espaçamentos utilizados de $0,90 \mathrm{~m}$ e $0,45 \mathrm{~m}$, bem como para a interação entre os fatores (Tabela 2). A exigência média, na operação de semeadura, ficou em 25,3 kW. As potências de pico e por fileira também não apresentaram diferenças estatísticas significativas ( $\mathrm{p}>0,05)$, nos três preparos do solo e nos dois espaçamentos estudados. O pico de potência foi, em média, 10-14\% maior que a média, demonstrando, assim, a importância desta variável no dimensionamento da escolha do trator com potência adequada.

Com relação às forças exigidas na barra de tração (média, de pico e por linha), verificou-se, pela análise estatística, que não houve efeitos significativos isolados dos fatores preparos do solo (convencional, escarificação e semeadura direta) e espaçamentos $(0,90 \mathrm{~m}$ e $0,45 \mathrm{~m})$, bem como da interação entre os

Tabela 2. Análise de variância e médias para as variáveis potência, potência de pico, potência por fileira, força de tração, força de tração de pico e força de tração por fileira, em função do preparo do solo e espaçamento de semeadura de milho (Jaboticabal, SP, 2007).

\begin{tabular}{|c|c|c|c|c|c|c|}
\hline \multirow[b]{2}{*}{ Fatores } & \multicolumn{3}{|c|}{ Potência } & \multicolumn{3}{|c|}{ Força de tração } \\
\hline & $\begin{array}{c}\text { Média } \\
(\mathrm{kW})\end{array}$ & $\begin{array}{l}\text { Pico } \\
(\mathrm{kW}) \\
\end{array}$ & $\begin{array}{c}\text { Por linha } \\
\left(\mathrm{kW} \text { linha }^{-1}\right)\end{array}$ & $\begin{array}{c}\text { Média } \\
(\mathrm{N})\end{array}$ & $\begin{array}{l}\text { Pico } \\
(\mathrm{N}) \\
\end{array}$ & $\begin{array}{c}\text { Por linha } \\
\left(\mathrm{N} \text { linha }^{-1}\right) \\
\end{array}$ \\
\hline \multicolumn{7}{|l|}{ Preparo $(P)$} \\
\hline Convencional & $27,7 \mathrm{a}$ & $32,2 \mathrm{a}$ & $4,0 \mathrm{a}$ & $18 \mathrm{a}$ & $20 \mathrm{a}$ & $2,5 \mathrm{a}$ \\
\hline Plantio direto & $25,7 \mathrm{a}$ & $29,3 \mathrm{a}$ & $3,6 \mathrm{a}$ & $16 \mathrm{a}$ & $18 \mathrm{a}$ & $2,2 \mathrm{a}$ \\
\hline Escarificação & $21,7 \mathrm{a}$ & $24,7 \mathrm{a}$ & $3,0 \mathrm{a}$ & $15 \mathrm{a}$ & $17 \mathrm{a}$ & $2,0 \mathrm{a}$ \\
\hline \multicolumn{7}{|l|}{ Espaçamento (E) } \\
\hline $0,90 \mathrm{~m}$ & $24,5 \mathrm{a}$ & $27,5 \mathrm{a}$ & $3,5 \mathrm{a}$ & $16 \mathrm{a}$ & $18 \mathrm{a}$ & $2,2 \mathrm{a}$ \\
\hline $0,45 \mathrm{~m}$ & $25,6 \mathrm{a}$ & $30,0 \mathrm{a}$ & $3,5 \mathrm{a}$ & $16 \mathrm{a}$ & $19 \mathrm{a}$ & $2,2 \mathrm{a}$ \\
\hline \multicolumn{7}{|l|}{ Teste F } \\
\hline $\mathrm{P}$ & $2,36^{\mathrm{ns}}$ & $2,75^{\mathrm{ns}}$ & $3,130^{\mathrm{ns}}$ & 1,440 ns & $1,60^{\mathrm{ns}}$ & $1,410^{\mathrm{ns}}$ \\
\hline $\mathrm{E}$ & $0,26^{\mathrm{ns}}$ & $0,96^{\mathrm{ns}}$ & $0,064^{\mathrm{ns}}$ & $0,004^{\mathrm{ns}}$ & $0,31^{\mathrm{ns}}$ & $0,0010^{\mathrm{ns}}$ \\
\hline $\mathrm{PXE}$ & $1,91^{\mathrm{ns}}$ & $1,76^{\mathrm{ns}}$ & $1,980^{\text {ns }}$ & $2,090^{\mathrm{ns}}$ & $1,56^{\mathrm{ns}}$ & $1,960^{\mathrm{ns}}$ \\
\hline CV (\%) & 22,44 & 22,4 & 22,81 & 23,17 & 23,15 & 22,98 \\
\hline
\end{tabular}

ns: não significativo $(\mathrm{p}>0,05)$; $*$ significativo $(\mathrm{p}<0,05)$; CV: coeficiente de variação. 
dois fatores. Furlani et al. (2005) não encontraram diferenças estatísticas entre os sistemas plantio direto e preparo convencional, para as variáveis força de tração $(13,3 \mathrm{kN})$ e potência $(27,3 \mathrm{~kW})$. Neste enfoque, Bortolotto et al. (2006) observaram diferenças significativas na força de tração na barra, quando trabalharam acima de $6,5 \mathrm{~km} \mathrm{~h}^{-1}$, na operação de semeadura, em Latossolo Vermelho distrófico. Com relação às forças exigidas na barra de tração (média, de pico e por linha), verificou-se, pela análise estatística, que não houve efeitos significativos isolados dos fatores preparos do solo (convencional, escarificação e semeadura direta) e espaçamentos $(0,90 \mathrm{~m}$ e $0,45 \mathrm{~m})$, bem como da interação entre os dois fatores. Estes resultados estão de acordo com os obtidos por Furlani et al. (2005) e Mahl et al. (2004), que, também, não encontraram efeito de diferentes sistemas de preparo do solo na força de tração média. Furlani et al. (2005) obtiveram valores médios de força de tração da ordem de $13,4 \mathrm{kN}$, em Latossolo Vermelho-Escuro eutrófico, enquanto Mahl et al. (2004) encontraram valores médios de $8,3 \mathrm{kN}$, em Nitossolo Vermelho distrófico. A força média por fileira de semeadura $\left(4,1 \mathrm{kN}\right.$ fileira $\left.{ }^{-1}\right)$ encontra-se próxima à preconizada pela ASABE (2006), que deve ser de, aproximadamente, $3,4 \mathrm{kN}$ por fileira, com variação de $35 \%$, para mais ou para menos.

Com relação à patinagem (Tabela 3), na área de semeadura direta, os índices ficaram dentro da faixa proposta pela ASAE (1996), para solo firme, que é de $8 \%$ a $10 \%$, enquanto, no preparo com escarificação, as patinagens foram superiores a estes limites e, também, superiores aos valores obtidos para a semeadura direta. Tal resultado deve-se ao fato de os terrenos preparados com escarificador resultarem em maior mobilização do solo, quando comparados com a semeadura direta, aumentando a patinagem dos rodados, sendo estes resultados corroborados por Furlani (2000). Resultados contrários foram encontrados por Mahl (2006), evidenciando que a palhada, na superfície do solo, dificulta a aderência dos rodados do trator ao solo, podendo aumentar a patinagem dos mesmos, causando, por consequência, aumento significativo da demanda por força de tração e potência na barra. Com isto, a explicação para o resultado obtido é que, na semeadura direta, por não haver revolvimento do solo, a rugosidade do terreno se mantém, resultando em menor patinagem das rodas, pois a superfície não revolvida apresenta menores obstáculos ao rolamento dos rodados.

Apenas para a roda traseira direita (RTD) foi evidenciada diferença significativa $(p>0,05)$ para patinagem, em relação aos dois espaçamentos estudados, sendo maiores os valores obtidos para o espaçamento de $0,90 \mathrm{~m}$ (Tabela 3). A quantidade de massa seca depositada sobre o solo não diferiu $(p>0,05)$ entre os preparos de solo, assim como para os dois espaçamentos analisados (Tabela 3). Os resultados podem ser atribuídos ao fato de ser este o primeiro ano da adoção dos sistemas conservacionistas, uma vez que, com o passar dos anos, haverá tendência de acúmulo de massa sobre a superfície do solo, no sistema plantio direto, devido à menor mobilização do solo.

Tabela 3. Análise de variância e médias para as variáveis patinagem, massa, velocidade e rotação no motor, em função do preparo do solo e espaçamento de semeadura de milho (Jaboticabal, SP, 2007).

\begin{tabular}{|c|c|c|c|c|c|c|c|}
\hline \multirow{2}{*}{ Fatores } & \multicolumn{4}{|c|}{ Patinagem } & \multirow{2}{*}{$\begin{array}{c}\text { Massa } \\
\left(\mathrm{kg} \mathrm{ha}^{-1}\right)\end{array}$} & \multirow{2}{*}{$\begin{array}{l}\text { Velocidade } \\
\left(\mathrm{Km} \mathrm{h}^{-1}\right)\end{array}$} & \multirow{2}{*}{$\begin{array}{l}\text { Rotação do } \\
\text { motor (rpm) }\end{array}$} \\
\hline & RTD & RTE & $\mathrm{RDD}$ & RDE & & & \\
\hline \multicolumn{8}{|c|}{ Preparo $(P)$} \\
\hline Convencional & $13 \mathrm{a} *$ & $12 a b$ & $12 \mathrm{ab}$ & $12 \mathrm{a}$ & $1.805 \mathrm{a}$ & $5,7 \mathrm{ab}$ & 2035 a \\
\hline Plantio direto & $8 \mathrm{~b}$ & $7 \mathrm{~b}$ & $7 \mathrm{~b}$ & $7 \mathrm{~b}$ & $1.592 \mathrm{a}$ & $5,8 \mathrm{a}$ & $2077 \mathrm{a}$ \\
\hline Escarificação & $14 \mathrm{a}$ & $13 \mathrm{a}$ & $14 \mathrm{a}$ & $13 \mathrm{a}$ & $1.492 \mathrm{a}$ & $5,3 \mathrm{~b}$ & $2002 \mathrm{a}$ \\
\hline \multicolumn{8}{|c|}{ Espaçamento (E) } \\
\hline $0,90 \mathrm{~m}$ & $13 \mathrm{a}$ & $11 \mathrm{a}$ & $13 \mathrm{a}$ & $12 \mathrm{a}$ & $1.624 \mathrm{a}$ & $5,4 \mathrm{a}$ & $2031 \mathrm{a}$ \\
\hline $0,45 \mathrm{~m}$ & $9 \mathrm{~b}$ & $10 \mathrm{a}$ & $10 \mathrm{a}$ & $9 \mathrm{a}$ & $1.635 \mathrm{a}$ & $5,7 \mathrm{a}$ & $2045 \mathrm{a}$ \\
\hline \multicolumn{8}{|l|}{ Teste $F$} \\
\hline $\mathrm{P}$ & $4,06 * *$ & $4,65 * *$ & $3,95 * *$ & $3,86 * *$ & $1,420^{\mathrm{ns}}$ & $5,46 * *$ & $1,60^{\mathrm{ns}}$ \\
\hline $\mathrm{E}$ & $4,92 * *$ & $0,41^{\mathrm{ns}}$ & $1,82^{\mathrm{ns}}$ & $2,13^{\mathrm{ns}}$ & $0,005^{\mathrm{ns}}$ & $3,35^{\mathrm{ns}}$ & $0,18^{\mathrm{ns}}$ \\
\hline PX E & $0,42^{\mathrm{ns}}$ & $0,58^{\mathrm{ns}}$ & $0,33^{\mathrm{ns}}$ & $0,30^{\mathrm{ns}}$ & $2,070^{\mathrm{ns}}$ & $3,15^{\mathrm{ns}}$ & $0,62^{\mathrm{ns}}$ \\
\hline $\mathrm{CV}(\%)$ & 38,05 & 39,4 & 45,54 & 42,04 & 23,28 & 6,34 & 4,15 \\
\hline
\end{tabular}


Para a velocidade de deslocamento (Tabela 3 ), os valores obtidos foram significativos $(p \leq 0,05)$, em relação ao preparo do solo, especificamente entre a semeadura direta (maior velocidade $=5,8 \mathrm{~km} \mathrm{~h}^{-1}$ ) e escarificação (menor velocidade $=5,3 \mathrm{~km} \mathrm{~h}^{-1}$ ). Este efeito deve-se à maior quantidade de palha nas áreas de semeadura direta, quando comparada com o uso do escarificador, efeito que pode ser atribuído ao contato eficiente do pneu com o solo, uma vez que boa parte da palha era composta por fragmentos ancorados e, portanto, promoveu melhor força de tração, refletindo, diretamente, no aumento da velocidade. Estes resultados discordam de Cepik et al. (2010), em estudo no qual afirmam que a patinagem aumenta, à medida que aumenta a quantidade de resíduos sobre o solo.

Os valores observados para a rotação do motor não apresentaram efeito significativo $(\mathrm{p}>0,05)$, em relação aos diferentes tipos de preparo do solo, ou seja, o terreno não influenciou na rotação do motor, durante a semeadura do milho (Tabela 3). A adoção de espaçamentos entre fileiras da semeadora-adubadora também não afetou a rotação do motor. Estes resultados eram esperados, a partir do momento em que não foram verificadas diferenças para força e potência na barra de tração, em função dos tratamentos aplicados.

Diante do exposto, a adoção de espaçamentos de $0,45 \mathrm{~m}$ e $0,90 \mathrm{~m}$, para a formação de cobertura vegetal, não afeta o desempenho operacional do conjunto trator-semeadora, nos diferentes sistemas de preparo do solo, para a cultura do milho.

\section{CONCLUSÕES}

1. Nas condições em que foi conduzido o trabalho, os espaçamentos da cultura do milho de $0,45 \mathrm{~m}$ e $0,90 \mathrm{~m}$, bem como os preparos de solo realizados, não afetaram a exigência de potência, força de tração e rotação do motor do trator, na operação de semeadura de milho.

2. A patinagem dos rodados, no sistema de semeadura direta, é menor, quando comparado ao preparo com escarificador. Portanto, a velocidade de deslocamento é maior na semeadura direta e menor no preparo do solo com escarificador.

\section{REFERÊNCIAS}

AMERICAN SOCIETY OF AGRICULTURAL AND BIOLOGICAL ENGINEERS (ASABE). ASAE D497.5: agricultural machinery management data. In: . ASABE standards 2006. St. Joseph: ASABE, 2006. p. 391-398.
AMERICAN SOCIETY OF AGRICULTURAL ENGINEERS (ASAE). Terminology and definitions for soil tillage and soil tool relationships. In: $A S A E$ standards: standards engineering practices data. St. Joseph: ASAE, 1982. p. 229-241.

AMERICAN SOCIETY OF AGRICULTURAL ENGINEERS (ASAE). Agricultural machinery management data: ASAE Standards S313.2. St. Joseph: ASAE, 1996.

BORTOlOtTo, V. C.; PINHEIRO NETO, R.; BORTOlOtTO, M. C. Demanda energética de uma semeadora-adubadora para soja sob diferentes velocidades de deslocamento e coberturas do solo. Engenharia Agrícola, Jaboticabal, v. 26, n. 1, p. 122-130, jan./abr. 2006.

CEPIK, C. T. C.; TREIN, C. R.; LEVIEN, R. Força de tração e volume de solo mobilizado por haste sulcadora em semeadura direta sobre campo nativo, em função do teor de água no solo, profundidade e velocidade de operação. Engenharia Agrícola, Jaboticabal, v. 25, n. 2, p. 447-457, 2005.

CEPIK, C. T. C. et al. Força de tração e mobilização do solo por hastes sulcadoras de semadoras-adubadoras. Revista Brasileira de Engenharia Agrícola e Ambiental, Campina Grande, v. 14, n. 5, p. 561-566, 2010.

CORTEZ, J. W. et al. Avaliação de uma semeadoraadubadora em sistema de plantio direto para a cultura da soja. Engenharia na Agricultura, Viçosa, v. 13, n. 4, p. 268-276, out./dez. 2005.

DA ROSA, D. P. et al. Relação entre solo e haste sulcadora de semeadora em Latossolo escarificado em diferentes épocas. Pesquisa Agropecuária Brasileira, Brasília, DF, v. 43, n. 3, p. 395-400, 2008.

EMPRESA BRASILEIRA DE PESQUISA AGROPECUÁRIA (Embrapa). Sistema brasileiro de classificação de solos. 2. ed. Rio de Janeiro: Embrapa, 2006.

FURLANI, C. E. A. Efeito do preparo do solo e do manejo da cobertura de inverno na produtividade da cultura do feijoeiro (Phaseolus vulgaris L.). 2000. 218 f. Tese (Doutorado em Energia na Agricultura)-Universidade Estadual Paulista, Botucatu, 2000.

FURLANI, C. E. A.; GAMERO, C. A.; LEVIEN, R. Semeadora-adubadora de fluxo contínuo: desempenho operacional em função de diferentes condições de preparo e cobertura do solo. Engenharia Agrícola, Jaboticabal, v. 22, n. 1, p. 60-67, 2002.

FURLANI, C. E. A.; SILVA, R. P.; LOPES, A. Avaliação de semeadora-adubadora de precisão trabalhando em três sistemas de preparo do solo. Engenharia Agrícola, Jaboticabal, v. 25, n. 2, p. 458-464, maio/ago. 2005. 
GARCIA, L. C. et al. Influência da velocidade de deslocamento na semeadura do milho. Engenharia Agricola, Jaboticabal, v. 26, n. 2, p. 520-527, maio/ago. 2006.

MAHL, D. Desempenho de semeadora em função de mecanismo de corte, velocidade e solos, no sistema plantio direto do milho. 2006. $143 \mathrm{f}$. Tese (Doutorado em Energia na Agricultura)-Faculdade de Ciências Agronômicas, Universidade Estadual Paulista, Botucatu, 2006.

MAHL, D. et al. Demanda energética e eficiência da distribuição de sementes de milho sob variação de velocidade e condição de solo. Engenharia Agrícola, Jaboticabal, v. 24, n. 1, p. 150-157, 2004.
NAGAOKA, A. K.; NOMURA, R. H. C. Tratores: semeadura. Cultivar Máquinas, Pelotas, v. 18, n. 1, p. 2426, mar. 2003.

SILVA, S. L. Avaliação de semedoras para plantio direto: demanda energética, distribuição longitudinal e profundidades de deposição da semente em diferentes velocidades de deslocamento. 2000. $123 \mathrm{f}$. Tese (Doutorado em Energia na Agricultura)-Faculdade de Ciências Agronômicas, Universidade Estadual Paulista, Botucatu, 2000. 